\title{
The Effect of Concentration Training on Shooting Free Throw in Basketball Game
}

\author{
Oki Candra \\ Department of Physical Education Health and Recreation, Faculty of Teacher Training and Educational Science, Universitas Islam \\ Riau, Pekanbaru, 28284. Riau, Indonesia
}

Received September 22, 2020; Revised November 25, 2020; Accepted December 22, 2020

\begin{abstract}
Cite This Paper in the following Citation Styles
(a): [1] Oki Candra , "The Effect of Concentration Training on Shooting Free Throw in Basketball Game," International Journal of Human Movement and Sports Sciences, Vol. 8, No. 6A, pp. 29-35, 2020. DOI: 10.13189/saj.2020.080705.
\end{abstract}

(b):Oki Candra (2020). The Effect of Concentration Training on Shooting Free Throw in Basketball Game. International Journal of Human Movement and Sports Sciences, 8(6A), 29-35. DOI: 10.13189/saj.2020.080705.

Copyright $(2020$ by authors, all rights reserved. Authors agree that this article remains permanently open access under the terms of the Creative Commons Attribution License 4.0 International License

\begin{abstract}
This study aimed to determine whether there is an effect of concentration training on shooting free throws by female students in basketball extracurricular. This research was a quantitative research using experimental design. The research design used was a pre-test post-test system aimed to ensure the effectiveness of the treatment given. The population in this study was basketball extracurricular students at State Senior High School 10 Pekanbaru consisted of 15 students. Sampling was done by using total sampling technique which all of them were used as samples. The t value obtained based on the findings of research using the $t$ test was 3.49. The results of this calculation were then consulted on the $t$ table with 14 degrees of freedom, so that the t table obtained was 1.76. In other words, $t$ count was greater than $t$ table which indicated a significant difference between the pre-test and post-test results of 3.86 and 5.13 , respectively. The increase in this value was found through the following steps: It was known that there has been an increase of $32.4 \%$ from the $\mathrm{t}$ table calculation as the difference between the results of the pre test and post test. Based on the research findings, the conclusion obtained is concentration training affects the shooting basketball free throws.
\end{abstract}

Keywords Concentration, Training, Shooting, Free Throw, Extracurricular Activities, Basketball

\section{Introduction}

Basketball is an effective means of student physical education. It is because basketball can facilitate the development of a harmonious, complex and comprehensive influence on organisms as well as strengthening health [1]. Basketball is one of the branches of big ball game which is very interesting to watch where this game has certain characteristics [2]. Basketball has gained its own popularity around the world as players and spectators are captivated by its dynamic characteristics of the team. There are several basic techniques that basketball players must master, such as dribbling, passing and shooting. Shooting is one of the three techniques that aim to enter the ball into the opponent's ring. Putting the ball into the opponent's ring is the main goal to win the game. It makes the shooting should be doneusing good techniques. This technique must be mastered properly and correctly by a basketball player. According to [3], it is explained that the game of basketball is played by 2 teams, each consisting of 5 players. The aim of this game is by putting the ball into rival team's ring and trying to prevent the rival team to put the ball into the ring [4]. Accuracy is needed to make the shooting technique to run well and get the ball into the ring. According to [5] winning in basketball is determined by how many balls are put in the ring. The more balls are put into the ring, the greater the chance for the team to win the game will be.

This effort should also be supported by shooting skills. This ability is a very important skill to play basketball. Shooting is defined as the basic basketball skill most familiar to and enjoyed by any players with their instinct to score goals. Shooting can be concluded as an attempt to get the last move that aims to get a point by putting the ball into the opponent's basketball ring [6]. If a player 
cannot get the ball or shoot it into the ring, that player will not win the match. Shooting is a decisive element in winning a match. A win is determined by the advantage of the number of shots enter the ring compared to that received by the opponent. Each team that has control of the ball must always look for opportunities to shoot.

Shooting requires constant practice. It is the ultimate goal of every game. The success of a team in a game is always determined by its success in shooting. Good shooting is supported by mastery of the correct technique [7]. Therefore, this shooting is considered to be a basic technique that must be learned properly and correctly by practice. [8] This is like basketball's objective, to put the balll as many as possible into the opposing team's ring and prevents them from doing the same on its side.

The ability owned by a player of shooting skills affect the results achieved in a match. It is stated that the success of a team is always determined by the success of the players in shooting, especially in getting a shooting free throw. According to [9] shooting free throw is the basic technique of playing basketball that will determines whether a team can win the game. In accordance with the statement of [10], the characteristics of basketball (open skill) makes shooting the ball into the ring is one of the many shooting techniques which aims to put the ball into the ring. Athlete who has good concentration in doing shooting and is supported by his physical condition, will make him to get higher chances on better shooting results and on target.

A player must learn good mental skills to do shooting, including concentration. When a player performs a shooting free throw, he must focus on the target and ignore any distraction. For this reason, high concentration is needed since with good concentration, focus and good technique, the ball thrown by a player is likely on target. According to [11] concentration is attention to an object which is also the ability to think completely on a particular task or job. The role of concentration is very important so that the players' attention is focused on the game, on tactics or strategies to play their best. Meanwhile, [12] stated that concentration can be defined as a state in which a person's consciousness is fixated on a certain object within a certain time.

According to [13] the relationship between concentration level and shot accuracy decrease or even fail, if a player has a low concentration. [14] stated that the determinants of accuracy in this case are: (a) high coordination, means that it requires good accuracy, (b) target size, (c) distance to target distance, (d) mastery of techniques, (e) speed movement, (f) athlete's feeling and precision. According to [15] things may cause loss of concentration includes internal and external factors, such as anxiety, thinking too much about the results will be obtained, thinking about opponents too much and so on. Concentration is an important part of every life activities. A person can do activities well if he/she has high concentration abilities. The need for high concentration is because there are various activities that must be done which are very complex, such as work, study and sports.

The opinions above explain that concentration is important in carrying out activities so that the results are as expected. If an athlete is unable to concentrate while he/she is in a match, it is likely that the result of the match will not be good as expected. This happen because good concentration can help to achieve maximum results. [16] suggested that distraction can result in decreased performance. Decreased performance in sports competition are such as the accuracy of throws, punches, kicks, or shots that are reduced, so that they are not on target.

On the other hand, there are factors affect the quality of a person's concentration. [10], divided these influences into internal and external, which is as follows. 1) Internal factors that affect concentration include: a) age, b) physicality, c) gender, d) knowledge and experience. 2) External factors may occur when: a) If there is a stimulus that is too strong, such as a very loud sound or shining light, such as a flash or camera flash, b) If the stimulus comes is something that is unusual or much different from the stimulus received, c) If the stimulus that comes is something extraordinary, 4) If the stimulus moves so that the attention of the player is not focused, is not monotonous and tends to see with the assumption and suspicion that there is a new stimulus.

Concentration is very much needed especially for sports that require players to always concentrate highly, include basketball. Accuracy is needed in basketball games. One of the most demanding techniques for high concentration in basketball is the shooting technique. A player is required to have high concentration when shooting into the basketball hoop. This is because concentration is related to the accuracy of the shot in basketball. [17] In previous studies on concentration, it was revealed that concentration is very influential in sports that require a high level of accuracy.

Based on some of the statements above, concentration is the ability to maintain full focus on a certain object within a certain time. In this case, a person is required not to be easily distracted by the surroundings. If a player is distracted by concentration, both internally and externally, it may result in a decrease in his performance as a player. This is the same for a student who cannot concentrate on shooting free throws which then makes the results he gets will not be optimal. In shooting, concentration is a very crucial to get the expected scores. Besides, it also requires excellent physical condition.

\section{Material Methods}

\subsection{Research Methods}

This research was a quantitative research using 
experimental experimental design. [18] Randomized Control Group Pretest-Posstest Design was used as the research design. This design is close to perfect considering that there is a control group and a treatment group with randomly placed subjects. The pretest-posttest in this study aimed to ensure the effectiveness of the treatment given. The research data were obtained through pre-test and posttest by doing concentration exercises. Initial data collection was carried out by assessing the ability to shoot free throws. Treatment actions in this study were carried out for 4 weeks where the training program was carried out 3 times a week, on Monday, Wednesday, and Friday. Concentration training material was presented at each meeting. It consisted of point observation exercises, eliminating the number ten on the target, describing the numbers by writing, observing the second shown in hour hand [19]

The population in this study was all basketball extracurricular students at State Senior High School 10 Pekanbaru totaling 15 students. Sampling in this study was conducted using a total sampling technique. The analysis technique in this research began with the prerequisite test. Testing the measurement results data related to the research results aimed to help the analysis process to make it better. The normality of the data in this study was tested with the help of SPSS 22 .

The instrument used for shooting a free throw according to [20] consists of: A basketball free throw test where the objective of the test was to determine the ability of an athlete to make a free throw in actual play. 1) basketball court with the hoop, 2) several baskets, 3) free shot instrument form, 4) stopwatch, 5) one person who tests the students, 6) one person who examines the results of free throws, 7) one person as caller participant, 8) free throw test form. The test started by instructing the participant who must be in a ready position on the half-circle line of the free throw. After being given the signal of "Start", the participant must run under the basketball hoop and return to the semicircle in 24 seconds. After that, the participant can make 10 free throws. The basis for scoring is that every ball enters the ring will get one point.

Table 1. Descriptive Statistics

\begin{tabular}{cccccc}
\hline & $\mathrm{N}$ & Minimum Maximum & Mean & Std. Deviation \\
\hline Pre-Test & 15 & 1,00 & 6,00 & 3,8667 & 1,59762 \\
Post-Test & 15 & 2,00 & 8,00 & 5,1333 & 1,84649 \\
$\begin{array}{c}\text { Valid N } \\
\text { (listwise) }\end{array}$ & 15 & & & & \\
\hline
\end{tabular}

\subsection{Mathematical Equations}

According to [21] following is the formula used in this study, namely the pre-test formula and the post-test formula:

$$
\begin{aligned}
& t=\frac{\sum D}{\sqrt{\frac{N \sum D^{2}-\left(\sum D\right)^{2}}{N-1}}} \\
& \text { Enhancement }=\frac{M_{D}}{M_{\text {pre }}} \times 100 \%
\end{aligned}
$$

\section{Findings and Discussion}

The findings obtained from this study were intended to describe the data, both data derived from pre-test and post-test. The pre-test data obtained from N 15 had the lowest (minimum) value of 1.0; the highest value (maximum) 0.6; average (mean) 3.86; and the standard deviation (SD) was 1.597. Meanwhile, in the posttest score, the lowest (minimum) score obtained was 2.0; highest value (maximum) 8.00; mean (mean) 5,133; mean and standard deviation (SD) 1.84. The details of the finding is presented below:

Table 2. Frequency Distribution of Pre-test: The Effect of Concentration Training on Shooting Free Throw in Basketball Game

\begin{tabular}{cccccc}
\hline The Interval Class & $\begin{array}{c}\text { The Absolute } \\
\text { Frequency }\end{array}$ & $\begin{array}{c}\text { The Relative } \\
\text { Frequency (\%) }\end{array}$ & $\begin{array}{c}\text { The Cumulative } \\
\text { Frequency }\end{array}$ & $\begin{array}{c}\text { The Relative-Cumulative } \\
\text { Frequency (\%) }\end{array}$ \\
\hline 1 & $6-6$ & 2 & 13.33 & 2 & 13.33 \\
2 & $5-5$ & 4 & 26.67 & 6 & 40 \\
3 & $4-4$ & 4 & 26.67 & 10 & 66.67 \\
4 & $3-3$ & 2 & 13.33 & 12 & 80 \\
5 & $2-2$ & 1 & 6.67 & 13 & 86.67 \\
6 & $1-1$ & 2 & 13.33 & 15 & 100 \\
\hline \multicolumn{7}{r}{} \\
\hline
\end{tabular}


The result obtained from the pretest exercises which examine the effect of concentration training on basketball free throw shooting is presented in the table 2 above. The first interval class 6 - 6 consists of 2 students (13.33\%), the second interval class between 5 - 5 consists of 4 students $(26.67 \%)$, the third interval class between $4-4$ consists of 4 students $(26.67 \%)$, the fourth interval $3-3$ amounts to 2 students (13.33\%), the fifth interval between 2 - 2 amounts to 1 student (6.67\%), and the sixth interval between 1 - 1 amounts to 1 student $(3.33 \%)$..

The table 3 presents that post test training is the results of concentration training's effect on free throw basketball shooting practice. There are several intervals obtained based on these data. The first interval class $8-7$ consists of 5 students $(33.33 \%)$, the second interval class between 6 - 5 is 5 students $(33.33 \%)$, the third interval class between $4-3$ is 4 students $(26.67 \%)$, and the fourth interval class between $2-1$ is 1 student $(6.67 \%)$.

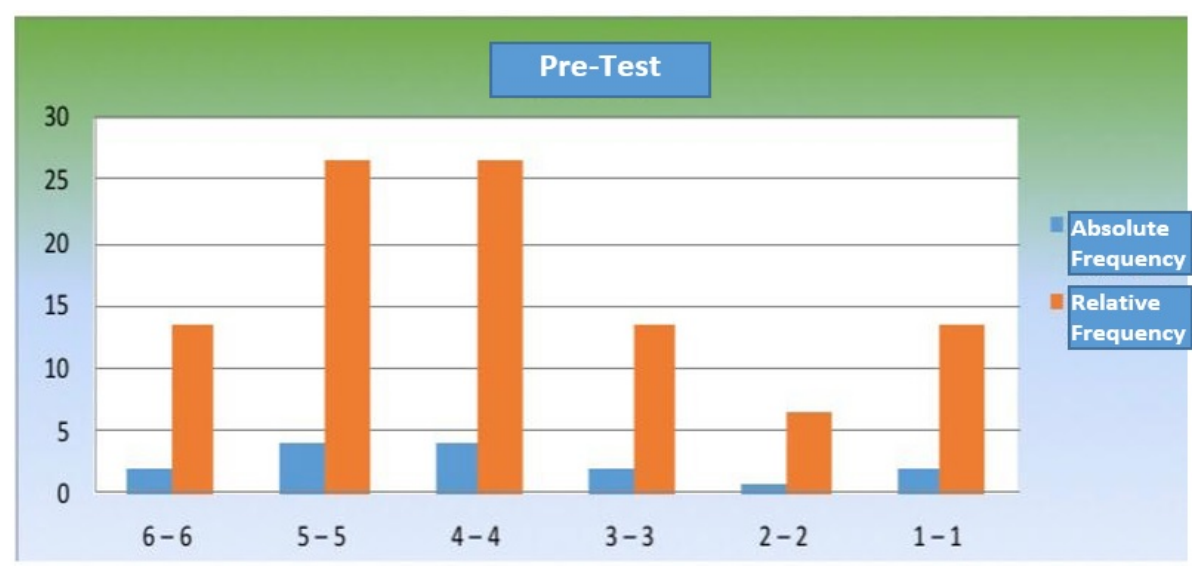

Graph 1. Bar Chart of Pre-test Exercises: The Effect of Concentration Training on Shooting Free Throw in Basketball Game

Table 3. Post-test Frequency Distribution: The Effect of Concentration Training on Shooting Free Throw in Basketball Game

\begin{tabular}{cccccc}
\hline & The Interval Class & $\begin{array}{c}\text { Absolute } \\
\text { Frequency }\end{array}$ & $\begin{array}{c}\text { Relative } \\
\text { Frequency(\%) }\end{array}$ & Cumulative Frequency & $\begin{array}{c}\text { Relative-Cumulative Frequency } \\
(\%)\end{array}$ \\
\hline 1 & $8-7$ & 5 & 33.33 & 5 & 33.33 \\
2 & $6-5$ & 5 & 33.33 & 10 & 66.67 \\
3 & $4-3$ & 4 & 26.67 & 14 & 93.33 \\
4 & $2-1$ & 1 & 6.67 & 15 & 100 \\
\hline
\end{tabular}

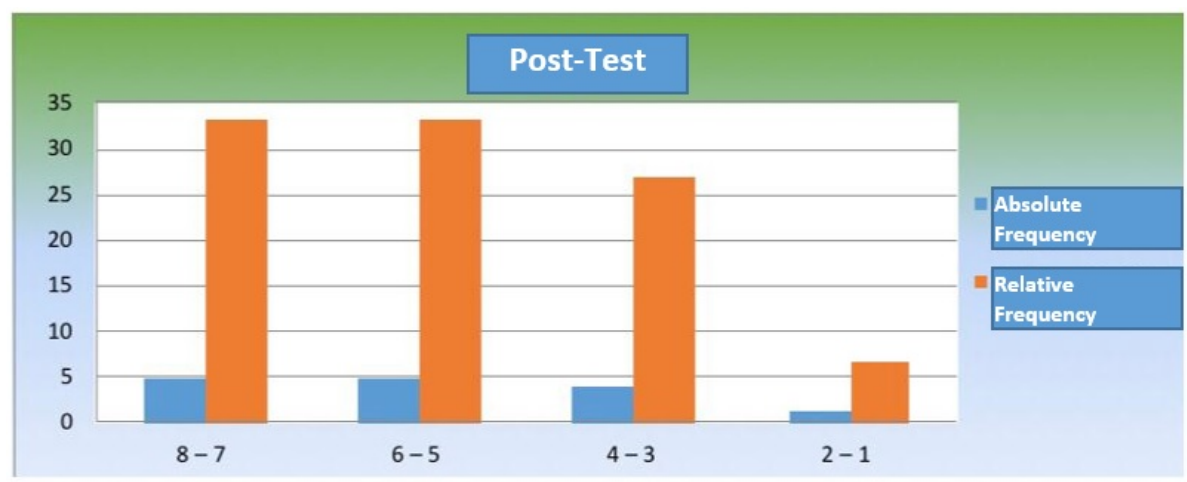

Graph 2. Post-test Exercise Bar Chart: The Effect of Concentration Training on Shooting Free Throw in Basketball Game 
The data must be normalized before the hypothesis testing was carried out. The results of the normality test were obtained using the Kolmogorov Smirnov method, both before and after the test. The following are the results of the normality test obtained:

Table 4. The Normality Result of Kolmogrove Smirnove (Pre-Test)

\begin{tabular}{cc}
\hline Statistics & Pre-Test \\
\hline N Sample & 15 \\
Mean & 3,867 \\
Standard Deviation & 1,598 \\
$\mathrm{D}_{\mathrm{n}}=$ & 0,133 \\
KS Table & 0,351 \\
& Normal \\
\hline
\end{tabular}

Table 5. The Normality Result of Kolmogrove Smirnov (Post-Test)

\begin{tabular}{cc}
\hline Statistics & Post-Test \\
\hline N Sample & 15 \\
Mean & 5,133 \\
Standard Deviation & 1,846 \\
$\mathrm{D}_{\mathrm{n}}=$ & 0,143 \\
KS Table & 0,351 \\
& Normal \\
\hline
\end{tabular}

After the pre-test and post-test data on basketball free throw shooting skills were described, the research hypothesis was tested by analyzing the entire data. The test aimed to determine whether the concentration training affects free throws from basketball shooting.

Table 6. The Result of T-test

\begin{tabular}{|c|c|c|c|c|c|}
\hline \multicolumn{2}{|c|}{ Mean } & \multirow{2}{*}{$\begin{array}{c}\text { Df } \\
(n-1)\end{array}$} & \multirow{2}{*}{$\begin{array}{c}T- \\
\text { count }\end{array}$} & \multirow{2}{*}{$\begin{array}{c}T- \\
\text { table }\end{array}$} & \multirow[b]{2}{*}{ Enhancement } \\
\hline Pre-Test & $\begin{array}{c}\text { Post- } \\
\text { Test }\end{array}$ & & & & \\
\hline 3.86 & 5.13 & 14 & 3.49 & 1.76 & $32,4 \%$ \\
\hline
\end{tabular}

According to the results of the $t$ test calculation shown in the table above, it shows that the $t$ value obtained is 3.49. The results of this calculation were consulted on $t$ table with 14 degrees of freedom so that the $t$ table obtained was 1.76 . This means that $\mathrm{t}$-count was greater than $\mathrm{t}$ table. It implied that there was a significant difference between the pre-test results with an average value of 3.86 and the post-test results with an average value of 5.13. The increase in this value was obtained through the following steps: Based on the calculations made, the increase obtained was $32.4 \%$. This value is the difference between the results of the pre test and post test. Therefore, it is concluded that concentration training has an effect on basketball free throws.

\section{Discussion}

Shooting free throws in basketball are the same as penalties in soccer. In the free throw technique, accuracy of body movement, ball speed and shooting time is required. Concentration is important to obtain precise accuracy. Fouls in play and penalties for such offenses are very frequent, one of which is penalty shots. Shooting free throw is shooting that is taken in the opponent's penalty area. Players in this case must maximize shots in order to generate points that can benefit the team. [22] Players often fail to make a shot due to improper technique, poor physical condition, and sometimes the lose of concentration due to pressure from the crowd or from teammates. The results of this study indicate that the concentration factor has a considerable influence. This influence is quite reasonable considering that without high concentration, players will not be able to shoot the ball properly because of external forces may reduce their performance and cause the ball miss the ring. This means that the better the concentration level of a player, the better his free throw skills. [23] The results of previous studies also found that there was a significant relationship between the concentration level of students and the accuracy of free throws in basketball games. It was also found that the level of student concentration greatly contributed to the accuracy of free throws in basketball games.

Concentration is one of the most important abilities to focus attention on the game with its various aspects, including the best playing tactics or strategies. The beneficial role of positive emotions found in this study is in line with the results of many previous studies investigated the same topic [24]. Concentration seems to be a familiar term among athletes. However, it is not easy to describe the limitations associated with this definition. The level of attention ability of sportsmen is one of the factors that support the success of a sports activity. Concentration can be defined as a state in which one's consciousness is fixated on a certain object within a certain period of time. The better a person's concentration, the longer a person can concentrate. If a player's concentration decreases or is interrupted during training, especially when the match is in progress, various problems will arise and make the results will less optimal. Thus, it can be assumed that the player who has high concentration is better than the player with low concentration regarding the accuracy of the free throw. If a player has good (high) concentration, he can do good free throw technique to get scores and vice versa. This problem is certainly bad for the team since they will have less opportunity to get points. Based on the description above, players who have high concentration are clearly better than players who have low concentration on shooting free throw accuracy.

The results of this study found that the concentration factor had a significant effect. The reason is because without high concentration, players will not be able to shoot the ball properly considering external distraction may damage performance and cause the ball miss the ring. 
This means that the better the concentration level of a player, the better his free throw ability. [25] Concentration is defined as the mental effort to put into the most important thing in any situation. Concentration is the ability to focus on relevant environmental cues. An athlete who is highly concentrated will do his job in the best possible way, make the learning process of new skills faster, increase self-confidence, able to control stress and anxiety by making good use of his experiences and focus on controlling factors. Internal factors that affect concentration are negative thoughts, fear, sadness, and worry.

[26] There are various things may affect the attention or concentration during a match. Experience teaches how a player can discern what is important to his performance and what should be ignored. However, this ability may take years. Athletes and their coaches can shorten this learning process by taking a little time to identify those areas that are indispensable for performance and those that are potential distractions. The trainer who is in charge of the young athletes needs to teach concentration training when the athlete is in a state of physical exhaustion and under the time limit. It is as a form of simulation training. Every sports skill has one kind of focus of concentration that aids performance and vice versa. For example, if a basketball player shooting a free throw is thinking about a previously failed attempt rather than focusing on the hoop where the ball should be put, he is likely to significantly increase his worry. This is because shooting the ball into the basket requires a narrow external focus rather than a wide internal focus.

Players are required to always focus on facing an obstacle in front of them, both physically and psychologically [27]. If a person has good concentration in carrying out activities, then the results of a movement he does will get good results too. In sport competition, if a player can focus and concentrate at the same time in doing something, then he can control the rhythm of the game and generate optimal points for the team. This happens considering that the player can make the opponent fooled or misstate in fighting for the ball from any situation. One example is when dribbling and unable to get past the enemy (opponent playing), then the shooting technique can be used to get points and win matches easily. Players must make sure that the shooting they do is precise and accurate to avoid the opponent grabbing the ball. In this case a good physical condition is needed.

A player with good physical condition will make him survive the pressure and physical disturbance of opposing players.[28] Explained that "The free throw shot is a basic movement that has advantages over other techniques". The advantage in question is that the player will not be hindered by the opposing player when he makes a free throw, so that the player can think more calmly and freely in adjusting his position and movement. The freedom of movement granted in making free throws should assist the player in scoring. However, this is not the case because the points generated are not comparable to the opportunities they have. It occurs because the player may make a movement that is less efficient. Some of the obstacles to movement may cause players to fail to get points include motion errors in the placement of the elbow position, throw position and balance. Referring to the quote above, it can be explained that at first glance the free throw shot looks easy to do, but in fact, many players cannot throw the ball right into the ring in this condition. Regardless the technical and physical perfection of the players, in fact, mental strength, concentration, peace of mind are also important. If all the supporting factors are owned by a player, the shooting free throw motion he makes will be more effective and efficient.

\section{Conclusions}

Based on the results of research using the $t$ test, the $t$ value obtained is 3.49 . The results of this calculation are then consulted on the $t$ table with 14 degrees of freedom, so that the $t$ table obtained is 1.76 . In other words, $t$ count is greater than $t$ table which indicates a significant difference between the average of pre-test and post-test, which is 3.86 and 5.13 respectively. The increase of this value is found through the following steps: It is known that there has been an increase of $32.4 \%$ from the $t$ table calculation where this value is the difference between the results of the pre test and post test. Therefore, it can be concluded that concentration training affects the shooting basketball free throws.

\section{REFERENCES}

[1] H. Z. Lavrin, "Technology of Concentrated Training as One of Ways to Optimization Students' Basketball Trainings," Phys. Educ. students, vol. 21, no. 2, p. 78, 2017, doi: 10.15561/20755279.2017.0205.

[2] O. Candra, "Contribution of Leg Muscle Explosive Power and Flexibility on Lay-Up Shoot in Basketball," 2019, pp. 480-482, doi: 10.2991/yishpess-cois-18.2018.121.

[3] Fiba, "Official Basketball Rules Basketball Equipment 2014," October, no. April, pp. 1-22, 2014.

[4] B. Aryanto, P. Sukoco, and R. Lumintuarso, "The Validity of Construct Analysis on Assessment Instrument of Basketball Skill for Senior High School In Yogyakarta City," International Journal of Human Movement and Sports Sciences, vol. 8, no. 5, pp. 193-198, 2020, doi: 10.13189/saj.2020.080506.

[5] S. S. Kusnanto, Setyo Aji \& Junaidi, "The Skill of Throw in The Ball into The Ring Based on The Concentration Value," JSSF (Journal Sport Sci. Fitness), vol. 1, no. 1, 2012.

[6] B. M. Indrayogi \& Heryanto, "Developing Shooting 
Learning Model in Basketball Game," J. Respecs, vol. 1, no. 2, 2007.

[7] A. R. S. Adiesta, Reno \& Tuasikal, "The Effect of Part Method Usage on The Result of Dribble and Shooting Skill Per Minute in Basketball," J. Educator. Sport, vol. 5, no. 3, pp. 483-489, 2017.

[8] O. Candra, "The Effect of Cooperative Method on Lay Up Shoot Skill of Basketball on Female Students of Grade VIII at State Junior High School 9 Pekanbaru," J. Sport Area, vol. 2, no. 1, pp. 45-52, 2017.

[9] R. Aryan, R. M., \& Mardela, "The Level of Athlete's Shooting Free Throw Skill," J. Patriot, vol. 2, no. 3, pp. 544-553, 2019, [Online]. Available: http://repositorio.unan. edu.ni/2986/1/5624.pdf.

[10] M. Burns, Bryan \& Dunning, Basketball Step By Step. United States: Rosen Central, 2010.

[11] M. Mashuda, I \& Purnomo, "The Contribution of Concentration, The Strength of Arm Muscle, The Strength of Leg Muscle, Back Flexibility on The Hit Towards The Outfield of Softball Sport," J. Sport Achievement, vol. 1, no. 1, 2013, [Online].Available:ejournal.unesa.ac.id/article/383 $1 / 67 /$ article.pdf.

[12] B. A. Harmono, "The Concentration Contribution on Punch Accuracy of Jumping Smash in Badminton," J. Health. Sport, vol. 2, no. 1, pp. 51-57, 2014.

[13] N. A. \& S. Kurniawan, "The Correlation Between The Students' Concentration Level and The Accuracy of Free Throw in Basketball Game (The Study on Participants of Basketball Extracurricular at State Senior High School 1 Sooko Mojokerto Academic Year 2013/2014," J. Phsycal Education, vol. 2, no. 1, pp. 249-252, 2014.

[14] I. Noerjannah and A. Sudijandoko, "he Concentration Contribution on The Accuracy of Volley Ball Top Serve on Female Players of Vocational High School 1 Kemlagi Mojokerto," J. Health. Sport, vol. 5, no. 2, pp. 47-50, 2016.

[15] M. Langenati, Ratih \& Jannah, "The Effect of Self-Hypnosis on Concentration of Artistic Gymnastic Athletes," Character J. Research. Psichology., vol. 3, no. 3, pp. 1-6, 2015.

[16] B. A. Febrianto, "The Correlation Between Concentration Level on The Accuracy of Kicking The Ball (Long Passing) for Football Players of Jombang Olympic Games," J. Health. Sport, vol. 4, no. 4, pp. 83-91, 2016.
[17] A. F. S. Arruda et al., "Influence of Competition Playing Venue on the Hormonal Responses, State Anxiety and Perception of Effort in Elite Basketball athletes," Physiol. Behav., vol. 130, pp. 1-5, 2014, doi: 10.1016/j.physbeh.2014.03.007.

[18] A. J. Naimatul, "The Effect of Concentration Training on The Accuracy of Jump Shoot and Free Throw in Basketball," J. Basic Educ. Sci., vol. 4, no. 1, pp. 37-42, 2020.

[19] W. D. Pilkey, Peterson's Stress Concentration Factors. 1997.

[20] Nurhasan \& A. Narlan. Sports Education Tests and Measurements. Physical Education, Health and Recreation. Siliwangi University., 2004

[21] A. Maksum, Statistics in Sports. Surabaya: Unesa University Press, 2009

[22] Showalter, Coaching Youth Basketball American Sport Education Program. 2012.

[23] N. Gillet, R. J. Vallerand, S. Amoura, and B. Baldes, "Influence of Coaches' Autonomy Support on Athletes' Motivation and Sport Performance: A test of the Hierarchical Model of Intrinsic and Extrinsic Motivation," $J$. Psychol. Sport Exerc., vol. 11, no. 2, pp. 155-161, 2010, doi: 10.1016/j.psychsport.2009.10.004.

[24] R. L. Vast, R. L. Young, and P. R. Thomas, "Emotions in Sport: Perceived Effects on Attention, Concentration, and Performance," Aust. Psychol., vol. 45, no. 2, pp. 132-140, 2010, doi: 10.1080/00050060903261538.

[25] Ç. Dereceli, "An Examination of Concentration and Mental Toughness in Professional Basketball Players," J. Educ. Train. Stud., vol. 7, no. 1, p. 17, 2018, doi: 10.11114/jets.v7i1.3841.

[26] Costas I. Karageorghis \& Peter C. Terry, Inside Sport Psychology. Australia: Human Kinetiks, 2011.

[27] D. Matthew and A. Delextrat, "Heart rate, Blood Lactate Concentration, and Time-Motion Analysis Of Female Basketball Players During Competition," J. Sports Sci., vol. 27, no. 8, pp. 813-821, 2009, doi: 10.1080/0264041090292 6420 .

[28] D. Abdulloh, I. N., Saichudin, S., \& Merawati, "The Movement Analysis of Free Throw on The Shooting Success in Basketball Team of Sport Science Faculty at Malang State University," J. Sport Sci., vol. 6, no. 2, 2018 